Rodrigo Quesada Monge Rosa Luxemburgo: utopía y vida cotidiana. (AUNA y NADAR, Heredia, Costa Rica. 2018, 471 págs.)

\title{
ROSA LUXEMBURGO. UTOPÍA Y VIDA COTIDIANA. Algunas consideraciones. Autor: Rodrigo Quesada Monge
}

\section{INTRODUCCIÓN}

La lectura de esta obra me ha resultado de gran interés por varias razones. En primer lugar, porque se inscribe en el ámbito de mis intereses historiográficos y de investigación. Segundo, por tratarse de un libro escrito de manera muy didáctica, reflejo del gran interés del autor por ser comprendido en sus objetivos de investigación, lo cual facilita asimilarlo en todos sus aportes. Por último, Rodrigo exhibe un alto perfeccionamiento y fidelidad con su oficio de historiador. Súmese a esto su envidiable disciplina para el trabajo intelectual. Sin duda, muy merecido el premio AQUILEO ECHEVERRÍA otorgado a esta valiosísima investigación por parte del Ministerio de Cultura. Mis felicitaciones.

\section{ROSA LUXEMBURGO Y SU CONTEXTO}

Antes que nada debemos tener presente que nosotros, hombres y mujeres, somos producto de una época y de las circunstancias históricas, culturales y geográficas en las que nos ha tocado vivir y actuar.

En ese sentido, la existencia física y social de Rosa Luxemburgo estuvo enmarcada desde los primeros intentos revolucionarios de la Comuna de París en 1871, año de su nacimiento, hasta el desastroso final de la Primera Guerra Mundial en noviembre de 1918. Pocos días después, el 15 de enero de 1919, ella sería asesinada por sus otrora correligionarios del Partido Socialdemócrata Alemán. En síntesis, se trató de una época tan convulsa e intensa como la vida misma de Rosa Luxemburgo.

La vida personal y política de este personaje fue particularmente difícil: mujer, discapacitada, revolucionaria, extranjera y judía, todo esto en un mundo de hombres sostenido y alimentado por las tradiciones patriarcales de las culturas judía y cristiana.

Como dato curioso, aunque no casual, a pocos días de la muerte de Rosa Luxemburgo - entre enero y julio de 1919 - el sociólogo alemán contemporáneo de Rosa, Max Weber, pronunciaría dos conferencias esenciales para el tema que aquí nos ocupa, publicadas luego en una de sus obras más conocidas: El político

\section{(C) $(\otimes \odot \odot$}

La Revista Estudios es editada por la Universidad de Costa Rica y se distribuye bajo una Licencia Creative Commons Atribución-NoComercial-CompartirIgual 3.0 Costa Rica. Para más información envíe un mensaje a 
ISSN 1659-3316

Aguilar Hernández Marielos

$\boldsymbol{y}$ el científico. Lo hizo en los propios días de la revolución alemana, en Baviera, ante un amplio auditorio de estudiantes de la Universidad de Munich para insistir en la inconveniencia de que la gente de ciencia incursionara en el mundo de la política. ¡Qué lejos quedaba esta recomendación del ejemplo que Rosa Luxemburgo le había brindado a la juventud de Alemania y del mundo, entregando su vida por un mundo mejor!

Una acotación más. A Rosa Luxemburgo le correspondió ser contemporánea y testigo de excepción del histórico Caso Dreyfus, un juicio militar de marcado tinte antisemita, efectuado en París por un consejo de guerra francés, cuyo veredicto en 1894 condenaba a un militar de bajo rango por, supuestamente, haberle brindado información muy sensible al agregado militar de Alemania en Francia. Más tarde quedaría demostrada la inocencia de Mathieu Dreyfus, cuyo principal "delito" era, en verdad, ser judío. ¡El antisemitismo crecía y crecía! Es en el contexto de esta disputa nacional -muchos intelectuales franceses denunciaron ardientemente la injusticia cometida contra Dreyfus- cuando se comienza a hablar específicamente de los intelectuales para referirse a su papel de críticos sociales y de su compromiso con la verdad y la justicia. Los liberales, en cambio, lo usaban en términos peyorativos para desacreditar sus mensajes cuestionadores. Lo anterior lo menciono porque la obra que esta noche comentamos, es, ante todo, una biografía intelectual. ¿Y qué significaba ser una intelectual de finales del siglo XIX y principios del siglo XX, como lo fue Rosa Luxemburgo? Esta es una interrogante clave para entender los aportes del libro que comentamos.

\section{LA OBRA DE RODRIGO QUESADA}

Por tratarse de una biografía intelectual, los aportes teóricos de Rosa Luxemburgo sobre el fenómeno de la revolución social, constituyen la columna vertebral del trabajo del autor. Los conceptos y las categorías que ella afina con tanto cuidado en torno a la transformación social europea de principios del siglo XX, son los fundamentos de esta obra.

El proyecto socialista que alimentó aquella corriente intelectual conformada por grandes profesionales de la revolución durante la segunda mitad del siglo XIX tuvieron en Karl Marx, Federico Engels, Rosa Luxemburgo, León Trotsky, Jorge Plejanov y Vladimir Lenin, para citar solo algunos de los más connotados, todo un equipo de pensadores que fueron capaces de hacer una lectura transformadora de la Europa moderna que había inaugurado la Revolución Francesa en 1789.

Al detenerse en la observación de los rasgos expansivos que asumía el capitalismo europeo a comienzos del siglo XX, Rosa Luxemburgo elaboró de manera muy didáctica la correlación histórica que ella misma constató entre los fenómenos del colonialismo y el imperialismo. Siguiendo el mismo procedimiento que Marx, Rosa Luxemburgo eligió como punto de partida de sus análisis históricos el caso del imperio inglés. Luego, el recurso metodológico de la historia comparada le permitió precisar los rasgos de la expansión imperialista de

\section{(C) $\odot \Theta \odot$}

La Revista Estudios es editada por la Universidad de Costa Rica y se distribuye bajo una Licencia Creative Commons Atribución-NoComercial-CompartirIgual 3.0 Costa Rica. Para más información envíe un mensaje a 
ISSN 1659-3316

Aguilar Hernández Marielos

Alemania, Francia y otros países y, a partir de ello, concebir y transmitir las tareas revolucionarias que le correspondían a la clase obrera europea de la época. Ese momento es el que nos permite apreciar a Rosa Luxemburgo como la gran mujer de pensamiento y acción que Rodrigo tan exhaustivamente estudia y que nos trae a colación un siglo después de su muerte.

Todas las preocupaciones coyunturales que Rosa Luxemburgo se permitió transmitirle a Europa y al mundo en las primeras décadas del siglo $X X$ se constataron con la catástrofe de la Primera Guerra Mundial y sus trágicas consecuencias, no solo con la destrucción material y humana de Europa sino con la estrepitosa caída del imperialismo alemán. Aún más, sus enseñanzas mantienen vigencia hasta nuestros días.

La militancia de Rosa Luxemburgo en el Partido Socialdemócrata Alemán y sus grandes contribuciones teóricas e ideológicas a la Segunda Internacional Socialista (1889-1919) se manifestaron también en el análisis que hace de otro fenómeno crucial en su época, a saber, la relación dialéctica entre patriotismo e internacionalismo. Esta perspectiva la afianza a ella en sus convicciones de revolucionaria antimilitarista.

Hay otro aspecto relevante que le interesa a Rosa Luxemburgo destacar sobre el momento en que le tocó desempeñarse como revolucionaria, es decir, sobre los años previos a la Primera Guerra Mundial: la expansión del militarismo y su gran amenaza para la paz mundial. El profundo análisis que realizó en este sentido, le permitió demostrar que el desarrollo de la industria militar no ha sido un hecho aislado o coyuntural, más bien ha resultado ser un eslabón inherente al desarrollo económico del capitalismo. La proximidad de la guerra de 1914 se lo develaba con gran claridad poco tiempo después.

Todo lo anterior lleva a Rosa Luxemburgo a polemizar fuertemente con algunos de sus compañeros de partido, quienes se habían encaminado hacia propuestas reformistas, pues consideraban que el capitalismo podía ser reformado para bien de los trabajadores y no necesariamente debía ser abolido. En esto sus adversarios principales fueron representados por el teórico alemán Edward Bernstein y el dirigente ruso Jorge Plejanov. Tales contradicciones llevaron al finalizar la Primera Guerra Mundial, ya en 1919, a la división irreversible de la Segunda Internacional Socialista en dos facciones, los socialdemócratas reformistas-parlamentaristas y los comunistas, convencidos estos de las bondades de la democracia ejercida por los consejos obreros y populares. Desde la perspectiva de Rosa y los suyos, las prácticas parlamentarias reñían con la democracia consejista como sustento real de una sociedad socialista. Para entonces los consejos obreros, o soviets, puestos en práctica por vez primera en la Rusia revolucionaria de 1905, recobraban su vigencia con la revolución bolchevique.

En estas duras discusiones, Rosa Luxemburgo dejaba muy claro un aspecto esencial: las revoluciones las hacen los pueblos, no solo los dirigentes. En esto discrepó con Lenin y con Trotsky, los grandes conductores de la Revolución Rusa de 1917, quienes le daban gran importancia a las vanguardias de revolucionarios

\section{(ब) $\odot \odot$}

La Revista Estudios es editada por la Universidad de Costa Rica y se distribuye bajo una Licencia Creative Commons Atribución-NoComercial-CompartirIgual 3.0 Costa Rica. Para más información envíe un mensaje a 
ISSN 1659-3316

Aguilar Hernández Marielos

profesionales encargados de conducir aquellos procesos de transformación social. A esto se sumaba la convicción de Rosa Luxemburgo del respeto merecido por quienes piensan diferente, ello como alimento para la democracia en el seno de los consejos obreros.

Las relaciones personales y amorosas de Rosa Luxemburgo que comenta el autor en algunos pasajes parecen muy sugestivas pero no me he detenido en ellas. Lo que sí me ha resultado sorprendente y a la vez doloroso constatar es que una mujer de tanto brillo no pudo escapar a la dependencia económica de su compañero Leo Joguiches, a sus agresiones de macho inseguro y hasta a sus amenazas de muerte. La cultura patriarcal se impuso. Esto sin subestimar los grandes aportes de Joguiches a la lucha revolucionaria en la Europa de principios del siglo XX.

Me llamó particularmente la atención la faceta periodística de Rosa Luxemburgo. Esto le permitió perfeccionar su estilo literario, compartir los resultados de sus investigaciones sobre el socialismo científico con los trabajadores alemanes, franceses y polacos, y, sobre todo, hacer una radiografía alternativa de la coyuntura histórica del mundo occidental a comienzos del siglo XX.

Por otra parte, el desempeño didáctico de esta extraordinaria mujer, como educadora de los obreros organizados en las filas de los partidos socialdemócratas, fue sumamente acertado. Recordemos que la misión de todo educador, o educadora, debe cumplirse con la aplicación de los propios descubrimientos académicos, obtenidos mediante la investigación propia y trasladados luego al ámbito de la enseñanza. En Luxemburgo esta transmisión del conocimiento fue ejemplar.

Sopesar a la Rosa periodista me remite a su época histórica y al surgimiento del intelectual como un actor social de primera línea. Coincidió en el tiempo con el ascenso del periodismo como una profesión diferenciada, ejercida por intelectuales que revolucionaron el mundo de la información, la política y la cultura. En este sentido, destacamos una vez más la capacidad de Rosa Luxemburgo para auto reivindicarse. Las labores intelectuales eran por entonces asunto de varones. Haber sido una pionera de la intelectualidad revolucionaria sin duda alguna constituye una excepción que aún hoy día es difícil de entender y superar.

Rosa la intelectual también fue una militante de gran disciplina desde sus diecinueve años, primero en su país natal, Polonia, en el GRUPO DEL PROLETARIADO y luego en el PARTIDO SOCIALDEMÓCRATA ALEMÁN, el más grande de Europa en aquel momento. Su militancia fue caldo de cultivo para su trabajo periodístico al servicio de la causa internacionalista y en contra de los nacionalismos, los patriotismos y los reformismos que enfermaron las raíces democráticas europeas.

Sobre sus reivindicaciones como mujer, creo que no lo puedo decir mejor que el propio Rodrigo: fue una feminista de hecho (p. 95). Para ella, todas las reivindicaciones sociales e históricas del proletariado, hombres y mujeres, eran posibles solamente en el marco de una sociedad socialista. De ahí que el

\section{(C) $\odot \Theta \odot$}

La Revista Estudios es editada por la Universidad de Costa Rica y se distribuye bajo una Licencia Creative Commons Atribución-NoComercial-CompartirIgual 3.0 Costa Rica. Para más información envíe un mensaje a 
feminismo de hoy día tiene en Rosa Luxemburgo un gran referente de lucha y liberación, un verdadero baluarte de las luchas femeninas.

Como gran ironía de la historia, fue la muerte de los principales líderes de la llamada LIGA ESPARTACO, entre ellos Rosa Luxemburgo y sus compañeros Leo Joguiches y Carl Liebknecht, la que inauguró aquel sangriento quinquenio revolucionario de la historia alemana (1918-1923) caracterizado por una violenta pugna en el seno de los socialdemócratas entre dos modelos posibles de sociedad: el reformista y el socialista. Finalmente, los esfuerzos de espartaquistas, comunistas y socialdemócrata independientes fracasaron para dar paso, temporalmente, a la llamada REPÚBLICA DE WEIMAR. Aún esta república reformista, mucho más inofensiva ante los intereses de las élites nacionalistas y monárquicas, resultó inaceptable para la extrema derecha alemana, la cual con su apoyo le dio paso firme al surgimiento del nazismo, al ascenso de Adolf Hitler y, más tarde, al desarrollo de la Segunda Guerra Mundial. Fueron quince años de experiencias muy dolorosas para el maltrecho pueblo alemán. En adelante, esa confrontación entre socialdemócratas y comunistas, que se prolongó durante casi todo el siglo XX, terminaría desgarrando al movimiento obrero internacional. La caída del Muro de Berlín en 1989 se encargó de hundir ambas alternativas.

\section{A MANERA DE EPÍLOGO}

Entre los diversos temas que se entrelazan en esta biografía de Rosa Luxemburgo, me ha llamado poderosamente la atención su doble condición de formadora e investigadora del movimiento obrero, sus luchas, sus estrategias y sus aspiraciones. Esto dio como resultado la gran intelectual revolucionaria que fue.

Por cierto, en una entrevista realizada en el 2013 al historiador italiano Enzo Traverso, por parte del antropólogo francés Regis Meyran, este le preguntó: ¿y qué fue de los intelectuales? Esto, a propósito de la crisis que este sector profesional y cultural exhibe hoy día. A sabiendas de que los intelectuales fueron sujetos de primera importancia en la construcción de un discurso crítico frente al capitalismo salvaje a lo largo del siglo XX, Traverso comenzó por afirmar: "Ahora vivimos en un presente constante... Luego del derrumbe del Socialismo Real el silencio de los intelectuales es el espejo de una derrota histórica, la de una utopía que iba mucho más allá de los regímenes políticos que pretendían encarnarla".

Lo anterior lleva al citado historiador a plantear una recomendación esencial: "Es urgente que elaboremos un pensamiento crítico renovado". ¡Cómo no asociar estas palabras con el aprendizaje obtenido en esta magnífica obra de Rodrigo Quesada!

Esto es todo un reto para los profesionales del presente y del futuro. Veremos cómo responden.

Dra. Marielos Aguilar Hernández Universidad de Costa Rica, Costa Rica

La Revista Estudios es editada por la Universidad de Costa Rica y se distribuye bajo una Licencia Creative Commons Atribución-NoComercial-CompartirIgual 3.0 Costa Rica. Para más información envíe un mensaje a 